\title{
PENGARUH MANAJEMEN PEMBELAJARAN GURU DAN GAYA BELAJAR TERHADAP KREATIVITAS BELAJAR SISWA SMP YAPENSORI JAKARTA UTARA
}

\author{
Eva Nurhayatih \\ Program Magister Manajemen Pendidikan Islam \\ Institut PTIQ Jakarta, Indonesia \\ Email : nurhayatihe91@gmail.com
}

\begin{abstract}
This study aims to determine and test empirical data related to the influence of teacher learning management and learning styles on student learning creativity in Yapensori Middle School, North Jakarta. In this study, the authors used a survey method with a correlational and regressional approach to quantitative data obtained from the research object, namely students of North Jakarta Yapensori Middle School. The sample of this research was 78 respondents from the 208 students of Yapensori North Jakarta Middle School. Data collection was carried out using a observation questionnaire, observation and regression technique which was described descriptively. The results of this study are:

First, there is a positive, strong and significant relationship between teacher learning management and student learning creativity, which is shown by the simple correlation coefficient (ry.1) is 0.292 (strong correlation) and the coefficient of determination (R2) $=0.085$, which means that learning management The teacher gives an influence on student creativity by $8.5 \%$ and the remaining $91.5 \%$ is determined by other factors. While the simple regression equation $\hat{Y}=67.752+$ $0.380 \times 1$, which means that each increase in one unit of the teacher learning management score will provide a tendency towards increasing student learning creativity by 0.380 .

Secondly, there is a positive, quite strong and significant relationship between learning styles and student creativity, which is shown by the simple correlation coefficient (ry.2) is 0.301 (the correlation is strong enough) and the coefficient of determination (R2) $=0.090$, which means that the learning style contributed to the creativity of student learning by $9.00 \%$ and the remaining $81.00 \%$ was determined by other factors. While the simple regression equation $\hat{Y}=70.004+0.344 \mathrm{X} 2$, which means that each increase of one unit of learning style score will provide a tendency to increase the score of student learning creativity 0.344 .

Third, there is a positive, strong and significant relationship between teacher learning management and learning styles together with student learning creativity, which is shown by the multiple correlation coefficient (Ry.1.2) is 0.330 (strong correlation) and the coefficient of determination $(\mathrm{R} 2)=0.109$, which means that the management of teacher learning and learning styles together provide an influence on
\end{abstract}


student creativity in learning $10.9 \%$ and the remaining $89.1 \%$ is determined by other factors. Whereas the multiple regression equation $\hat{Y}=58,752+0,224 X 1+0,223 X 2$, which means that every improvement in teacher learning management and learning styles together will provide a tendency towards increasing student creativity by 0.447 ..

Kata Kunci : Learning Management, Learning Style, Learning Creativity

\section{Pendahuluan}

Dalam proses kegiatan belajar mengajar kenyataannya pada saat ini kebanyakan seorang guru sering monoton dengan satu metode atau tidak mengvariasikan cara mengajarnya, serta kurangnya pemahaman guru tentang tipe gaya belajar siswa, sehingga pembelajaran yang di berikan kurang di pahami oleh siswa. Dengan gaya belajar siswa sebenarnya guru dapat membangkitkan kreativitas siswa yang mulanya tidak kreatif menjadi kreatif, yang awal mula pasif menjadi sedikit aktif dengan gaya belajar yang ia miliki. Pendekatan pendidikan seperti gaya belajar siswa perlu dilakukan karena pendidikan merupakan suatu kegiatan yang sengaja dilaksanakan dalam mencapai tujuan. Dengan adanya pendekatan ini, supaya guru dapat dengan mudah menyampaikan suatu materi kepada peserta didik. Sehingga dengan usaha pendekatan ini guru, selain sebagai motivator guru juga dapat memberikan materi pembelajaran sesuai dengan tujuan pembelajaran yang telah ditetapkan sesuai standar kompetensi dan kompetensi pedagogik guru tersebut. Belajar bukanlah menghafal sejumlah fakta atau informasi. Belajar adalah berbuat, memperoleh pengalaman tertentu sesuai dengan tujuan yang diharapkan. Karena itu, strategi pembelajaran harus dapat mendorong aktivitas siswa. Aktivitas ini tidak dimaksudkan terbatas pada aktivitas fisik, akan tetapi juga meliputi aktivitas yang bersifat psikis seperti aktivitas mental. Guru 
sering lupa dengan hal ini. Dan banyak guru yang terkecoh oleh sikap siswa yang pura-pura aktif padahal sebenarnya tidak. ${ }^{1}$

Kita ketahui bahwasanya kurilulum 2013 sudah di terapkan di setiap sekolah di Indonesia. Mulai tahun pelajaran 2013/2014, Pemerintah telah memberlakukan kurikulum baru yang disebut dengan Kurikulum 2013. Kurikulum 2013 merupakan kurikulum berbasis kompetensi yang menekankan pembelajaran berbasis aktivitas, yang bertujuan untuk meningkatkan keaktifan, kreativitas. termaksuk di SMP Yapensori Jakarta Utara sudah mengikuti kebijakan pemerintah dengan menerapkan Kurikulum 2013. Dalam sistem penilaiannya di dalam kurikulum 2013 ada yang namanya penilaian keterampilan di dalam KD pada KI 4 bahwasanya: Penilaian keterampilan adalah penilaian yang dilakukan untuk mengukur kemampuan peserta didik dalam menerapkan pengetahuan dalam melakukan tugas tertentu di berbagai macam konteks sesuai dengan indikator pencapaian kompetensi. Penilaian keterampilan dapat dilakukan dengan berbagai teknik, antara lain penilaian praktik, penilaian produk, penilaian proyek, dan penilaian portofolio. Teknik penilaian keterampilan yang digunakan dipilih sesuai dengan karakteristik KD pada KI-4. ${ }^{2}$ Jika kurikulum 2013 sudah di terapkan di SMP Yapensori seharusnya kreativitas siswa sudah mulai muncul, kenyataan nya kurikulum sudah di terapkan di SMP Yapensori tetapi kreativitas siswa masih rendah. Pada kasus di atas maka saya menarik kesimpulan ada kejanggalan yang terjadi dalam sistem memanajemen pembelajaran guru yang mana kurikulum 2013 sudah di terapkan dan penilaian keterampilan sudah di berlakukan tetapi dalam hal kreativitas siswa belum muncul, maka berdasarkan fenomena-fenomena di atas, peneliti tertarik mengadakan penelitian sehubungan dengan pengaruh

\footnotetext{
${ }^{1}$ Wina Sanjaya, Strategi Pembelajaran, Jakarta: Prenadamedia Group 2006, cet, 12. Hal 123 ${ }^{2}$ https://www.republika.co.id/berita/kemendikbud/testimoni-k13/14/09/12/nbsgn5kurikulum-2013- tekankan-karakter-ciptakan-siswa-lebih-aktif-dan-kreatif di akses apada 05/09/2018 jam, 21:03
} 
manajemen pembelajaran guru dan gaya belajar siswa terhadap kreativitas belajar siswa di SMP Yapensori Jakarta Utara. Alasan peneliti memilih judul ini adalah sebagai berikut:

\section{Kajian Pustaka}

\section{Kreativitas Siswa}

Dalam Kamus Besar Bahasa Indonesia Kreativitas adalah kemampuan untuk berkreasi atau daya mencipta. ${ }^{3}$ Kreatif adalah kata dasar dari kreativitas, sedangkan kreativitas adalah aktivitasnya. Kata kreativitas berasal dari kata sifat kreatif yang berarti pandai mencipta. Sedangkan untuk pengertian yang lebih kuat, kreativitas berarti suatu proses yang tercermin dalamkelancaran, kelenturan (fleksibilitas) dan orisinalitas berpikir. 4 Kreativitas adalah merupakan kemampuan untuk menciptakan sesuatu yang baru untuk memberi ide kreatif dalam memecahkan masalah atau sebagai kemampuan untuk melihat hubunganhubungan yang baru antara unsur-unsur yang sudah ada sebelumnya. ${ }^{5}$ Menurut Conny Semiawan, kreativitas adalah kemampuan untuk memberikan gagasan-gagasan baru dan menetapkannya dalam pemecahan masalah. Kreativitas meliputi baik ciri-ciri kogniif (aptitude) seperti kelancaran, keluwesan, (fleksibelitas) dan keaslian (orisinalitas) dalam pemikiran maupun ciri-ciri afekif (non-aptitude) seperti rasa ingin tahu, senang mengajukan pertanyaan dan selalu ingin mencari pengalaman baru.

Menurut Martini Jamaris, kreativitas belajar adalah kemampuan siswa untuk menemukan cara-cara yang baru dalam rangka menyelesaikan masalah-masalah yang berhubungan dengan pembelajaran. Menurut Moreno dalam Slameto, yang terpenting dalam kreativitas belajar itu bukanlah penemuan sesuatu yang belum pernah

\footnotetext{
${ }^{3}$ Kamus Besar Bahasa Indonesia, Jakarta: Balai Pustaka, 2005, hal. 377

${ }^{4}$ Dedi Supriadi. Kreativitas, Kebudayaan dan Perkembangan Iptek.

5 E.B Hurlock, Perkembangan Anak Jilid II. Alih Bahasa Meltasari Tjandrasa. Jakarta: Penerbit Erlangga 1980, hal. 3
} 
diketahui orang sebelumnya melainkan produk kreativitas itu merupakan sesuatu yang baru bagi diri sendiri yang tidak harus merupakan sesuatu yang baru bagi orang lain atau dunia pada umumnya. Kreativitas merupakan salah satu potensi penting yang dimiliki anak yang perlu di kembangkan sejak usia dini. Setiap anak memiliki bakat yang kreatif dan ditinjau dari segi pendidikan yang didapat dari dorongan keluarga, sekolah, dan lingkunagn sekitar. Menurut David Campebell "kreativitas" mempunyai peran sangat besar bagi kesuksesan, demikian juga pada anak, peran kreativitas membentuk corak atau prilaku anak dalam hidup kesehariannya. ${ }^{6}$ Kreativitas adalah proses mental berhubungan dengan konsep-konsep pengalaman termasuk didalamnya susunan suatu gagasan baru.

\section{Manajemen Pembelajaran}

Manajemen adalah seni dan ilmu dalam prencanaan dan pengorganisasian, pengarah, permotivasian dan pengendalian terhadap orang dan mekanisme kerja untuk mencapai tujuan. Manajemen selain sebagai suatu ilmu juga sebagai suatu seni. Sebagaimana suatu ilmu, manajemen merupakan akumulasi pengetahuan yang telah disitematisasikan menjadi suatu kesatuan yang terpadu dan dapat dijadikan pegangan dasar dalam bertindak. Sedangkan sebagai seni adalah keahlian, kemampuan, kemahiran, serta keterampilan dalam aplikasi prinsip, metode, dan teknik dalam menggunakan sumberdaya manusia secara efesien dan efektif. ${ }^{7}$ Manajemen umumnya diartikan sebegai proses prencanaan, mengorganisasi, pengarahan, dan pengawasan. Usaha-usaha para anggota organisasi dan penggunaan sumberdaya organisasi lainnya agar mencapai tujuan organisasi yang telah ditetapkan. Inti dari manajemen adalah pengaturan.

${ }^{6}$ Juhan Taufiq Andrianto, Cara Cerdas Melejitkan IQ Kreatif Anak, Bandung: Remaja Rosdakarya, hal. 83

7 Siswanto, Pengantar Manajemen, Jakarta: Bumi Aksara, cet. Kelima. 2009, hal. 7 
Menurut padangan Al-Qur'an, manajemen terdapat beberapa aspek yaitu: Keteraturan alam semesta ciptaan Allah sebagai mana tercantum dalam firman-Nya surah Al-Muluk 67 ayat 3-4

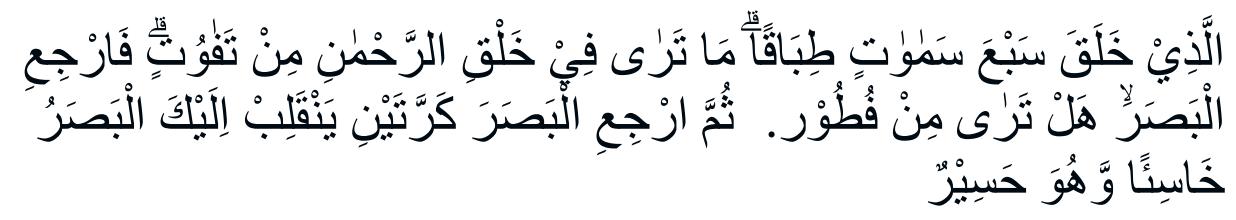

"yang telah menciptakan tujuh langit berlapis-lapis. kamu sekali-kali tidak melihat pada ciptaan Tuhan yang Maha Pemurah sesuatu yang tidak seimbang. Maka lihatlah berulang-ulang, Adakah kamu Lihat sesuatu yang tidak seimbang?" "Kemudian pandanglah sekali lagi niscaya penglihatanmu akan kembali kepadamu dengan tidak menemukan sesuatu cacat dan penglihatanmu itupun dalam Keadaan payah"( Q.S. Al-Muluk 64 :3-4).

Dalam tafsir jalalain pada ayat 3 bahwa yang menciptakan tujuh langit berlapis-lapis yakni sebagaian diantaranya berada diatas sebagian yang tanpa bersentuhan. Maka kamu sekali-sekali tidak melihat ciptaan yang Maha Pemurah pada tujuh langit yang berlapis-lapis itu ada makhluk yang lain. Untuk sesuatu yang tidak seimbang yang berbeda dan tidak seimbang. Maka lihatlah berulang-ulang artinya lihatlah kembali ke langit adakah kamu lihat padanya keretakan? Maksudnya retak dan berbelah-belah. Sementara pada ayat ke 4, kemudian pandanglah sekali lagi, ulangilah lagi penglihatanmu berkali-kali, niscaya akan berbalik, akan kembali penglihatanmu itu kepada mu dalam ke adaan hina. Karena tidak menemukan sesuatu yang cacat dan penglihatanmu itu pun dalam keadaan payah, yakni tidak melihat sama sekali adanya kecacatan. ${ }^{8}$

\section{Gaya Belajar}

Setiap individu memiliki kekhasan sejak lahir dan diperkaya melalui pengalaman hidup. Yang pasti semua orang belajar melalui alat indrawi, baik penglihatan, pendengaran, dan kinestetik (sentuhan/ gerakan). Setiap orang memiliki kekuatan belajar atau gaya belajar yang dimiliki maka akan semakin mudah dan lebih percaya diri dalam menguasai

${ }^{8}$ As-Suyuthi Imam, Tafsir Jalalain, Jilid, 4, 2498. 
keterampilan dan konsep-konsep dalam kehidupan. Gaya belajar menurut Keefe yang dikutip dari Sri Rumini adalah suatu karakteristik kognitif, afaktif dan perilaku psikomotorik, sebagai indikator yang bertindak relative stabil untuk pembelajar merasa saling berhubungan dan beraksi terhadap lingkungan belajar. Gaya belajar merupakan cara yang bersifat individu untuk memperoleh dan menyerap informasi dari lingkungannya, termasuk lingkungan belajar. Definisi lain dikemukakan oleh Kolb yang menyatakan bahwa gaya belajar merupakan metode yang dimiliki individu untuk mendapatkan informasi, yang pada prinsipnya gaya belajar merupakan bagian integral dalam siklus belajar aktif. Gaya belajar adalah cara-cara yang lebih kita sukai dalam melakukan kegiatan berpikir, memperoses dang mengerti suatu informasi. ${ }^{9}$ Sedangkan menurut Nasution yang dinamakan gaya belajar adalah cara konsisten yang dilakukan oleh seorang murid dalam menangkap stimulus atau informasi, cara mengingat, berpikir dan memecahkan masalah. ${ }^{10}$ Tidak semua siswa mempunyai gaya belajar yang sama, sekalipun bila mereka bersekolah disekolah atau bahkan duduk dikelas yang sama.

Pengetahuan tentang gaya belajar siswa sangat penting untuk diketehui oleh guru, orang tua, dan siswa itu sendiri, karena pengetahuan tentang gaya belajar ini dapat digunakan untuk membantu memaksimalkan proses pembelajaran agar hasil pembelajaran dapat tercapai sesuai dengan tujuan yang diharapkan.11 Gaya belajar yang dimaksud dalam penelitian ini adalah cara yang digunakan oleh siswa dalam menyerap informasi atau materi pelajaran berdasarkan pendekatan preferensi sensori. Yaitu gaya belajar yang dilakukan dengan cara memasukan informasi kedalam otak melalui modalitas indra yang

\footnotetext{
${ }^{9}$ M. Nur Ghufron dan Rini Risnawati, S, Gaya Belajar Kajian Teoretik, Yogyakarta: Pusaka Pelajar, 2013, hal. 10-11.

${ }^{10}$ Nasution, Berbagai Pendekatan dalam Proses Belajar Mengajar, Jakarta: PT. Bumi Askara, 2009, hal. 94.

11 Adi W. Gunawan, Genius Learning Strategy, Petunjuk Praktis untuk Bermain untuk Membuka Pikiran Anak-anak Anda, terj. Rahmi Astuti, Bandung: Kaifa, 2002, hal. 146.
} 
dimiliki. Gaya belajar adalah kunci untuk mengembangkan kinerja dalam pekerjaan, disekolah, dan dalam situasi-situasi antar pribadi siswa. Gaya belajar siswa adalah kombinasi dari bagai mana ia menyerap, dan kemudian mengatur serta mengolah informasi. Menurut Bobbi De Porter ia mengatajan bahwa gaya belajar ada tiga macam, yaitu visual, auditorial, dan kinestetik. ${ }^{12}$

\section{Metode Penelitian}

penelitian ini menggunakan metode survai dengan pendekatan korelasional. Metode survai dipergunakan dengan pertimbanganpertimbangan bahwa penelitian dilakukan untuk mendapatkan data setiap variabel masalah penelitian dari tempat tertentu yang alamiah (bukan buatan) dengan alat pengumpul data berbentuk angket (kuesioner), test dan wawancara terstruktur dan berdasarkan pandangan dari sumber data, bukan dari peneliti.

Dalam penelitian ini, subjek yang diteliti sebagai sumber data atau responden adalah siswa di SMP Yapensori Jakarta Utara. Mengingat terbatasnya waktu dalam penelitian ini, maka untuk menentukan guru sebagai sampel dalam penelitian ini peneliti menggunakan Nonprobability Sampling dengan teknik Sampling Sistematis, yaitu penentuan sampel berdasarkan urutan dari anggota populasi yang telah diberi nomor urut 178 dan yang diambil hanya yang mendapat nomor urut ganjil saja.

Variabel penelitian dalam penelitian ini meliputi tiga variabel penelitian yaitu variabel terikat kreativitas belajar siswa $(\mathrm{Y})$, variabel bebas manajemen pembelajaran guru $\left(X_{1}\right)$, variabel bebas gaya belajar $\left(X_{2}\right)$. Adapun skala pengukurannya menggunakan skala Likert dalam bentuk angket dengan lima alternatif jawaban.

Penelitian ini tergolong jenis penelitian kuantitatif, oleh karena itu, maka sifat data dalam penelitian ini termasuk data interval yaitu

\footnotetext{
12 Bobbi De Porter dan Mike Hernacki, Quantum Learning, Membiasakan Belajar Nyaman dan Meyenangka, Bandung: Kaifa, 2010, hal. 110-112
} 
data hasil pengukuran yang dapat diurutkan atas dasar kriteria tertentu yang diperoleh melalui kuesioner dengan skala Likert dengan alternatif jawaban yang diberi skor yang ekuivalen (setara) dengan skala interval, misalnya: skor (5) untuk jawaban "Sangat Setuju", skor (4) untuk jawaban "Setuju" skor (3), untuk jawaban "Kurang Setuju”, skor (2) untuk jawaban “Tidak Setuju", skor (1) untuk jawaban "Sangat Tidak Setuju" atau skor (5) untuk jawaban "Selalu", skor (4) untuk jawaban "Sering" skor (3), untuk jawaban "Kadang-kadang", skor (2) untuk jawaban "Pernah", skor (1) untuk jawaban "Tidak Pernah"

Teknik pengumpulan data dalam penelitian ini menggunakan beberapa teknik yaitu teknik penyebaran quesioner atau angket untuk mendapatkan data yang bersifat pendapat atau persepsi, yang dilanjutkan dengan pendalaman melalui wawancara dan observasi langsung ke sumber data. Agar angket yang dipergunakan dalam penelitian ini memiliki tingkat akurasi dan ketepatan yang tinggi dalam penggalian data penelitian.

$$
\mathrm{n}=\frac{\mathrm{N}}{\mathrm{N} \cdot \mathrm{d}^{2}+1}
$$

\section{Keterangan :}

$\mathrm{n}=$ Ukuran Sampel

$\mathrm{N}=$ Ukuran populasi

$\mathrm{d}^{2}=$ Nilai Presisi 95\% atau tingkat kekeliruan 5\%

1 = Konstanta

Pendapat lain tentang penentuan sampel ini dikemukakan Russeffendi ${ }^{13}$ yang menentukan sampel dengan ukuran pendekatan ratarata populasi dengan rumus sebagai berikut:

13 Russeffendi, E.T. Dasar-dasar Penelitian Pendidilkan dan Bidang Non Eksakta lainnya, Bandung, Tarsito, 1998, hal. 30 


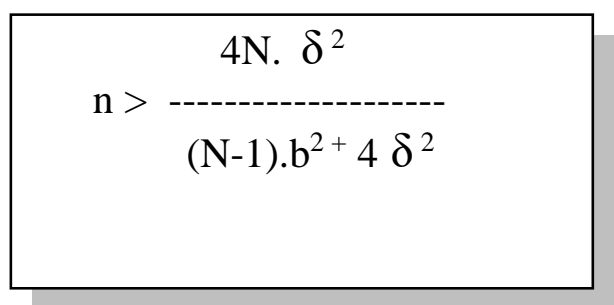

$\mathrm{n}=$ ukuran sampel

$\mathrm{N}=$ ukuran populasi

$\delta$ = simpang baku

b = batas kekeliruan estimasi error

Berdasarkan uraian di atas, maka dalam penelitian ini, peneliti menggunakan ukuran sampel jenuh dalam penelitian ini.

Tabel 1. Sebaran Sampel Dari Populasinya

\begin{tabular}{|l|l|l|l|}
\hline Sampel & Jenis Kelamin & Jumlah Populasi & Jumlah Sampel \\
\hline \multirow{2}{*}{ Siswa } & Laki-laki & 39 & 78 \\
\cline { 2 - 3 } & Perempuan & 39 & \\
\hline \multirow{2}{*}{ Jumlah } & & & 78 \\
\hline
\end{tabular}

Terdapat dua macam analisis/statistik yang digunakan untuk menganalisis data dalam penelitian, yaitu analisis/statistik deskriptif dan analisis/statistik inferensial. Analisis/statistik inferensial terdiri dari dua bagian yaitu statistik parametrik dan statistik nonparametrik.

Analisis deskriptif adalah analisis yang digunakan untuk menganalisis data dengan cara mendekripsikan atau menggambarkan data yang telah terkumpul sebagaimana adanya tanpa bermaksud membuat kesimpulan yang berlaku umum atau generalisasi. Analisis deskriptif dilakukan untuk mengetahui dan menyajikan jumlah responden $(N)$, harga rata-rata (mean), rata-rata kesalahan standar (Stadandard Error of Mean), median, modus (mode), simpang baku (Standard Deviation), varian (Variance), rentang (range), skor terendah 
(minimum scor), skor tertinggi (maksimum scor) dan distribusi frekuensi yang disertai grafik histogram dari kelima variabel penelitian.

Analisis inferensial sering juga disebut analisis induktif atau analisis probabilitas adalah teknik analisis yang digunakan untuk menganalisis data sampel dan hasilnya diberlakukan untuk populasi. ${ }^{14}$ Analisis inferensial digunakan untuk sampel yang diambil dari populasi dengan teknik pengambilan sampel secara random. Analisis inferensial ini disebut juga analisis probabilitas, karena kesimpulan yang diberlakukan untuk populasi berdasarkan data sampel yang kebenarannya bersifat peluang (probability). Suatu kesimpulan dari data sampel yang akan diberlakukan untuk populasi mempunyai peluang kesalahan dan kebenaran (kepercayaan) yang dinyatakan dalam bentuk prosentase. Bila peluang kesalahan 5\%, maka taraf kepercayaan 95\% dan bila peluang kesalahan 1\%, maka taraf kepercayaan 99\%. Peluang kesalahan dan kepercayaan ini disebut dengan istilah "taraf signifikansi".

\section{Hasil Penelitian}

Untuk membuktikannya, maka penelitian ini mengajukan tiga hipotesis yang pembuktiannya perlu diuji secara empirik. Ketiga hipotesis tersebut adalah merupakan dugaan sementara tentang pengaruh manajemen pembelajaran guru $\left(X_{1}\right)$, gaya belajar $\left(X_{2}\right)$ baik secara sendiri-sendiri maupun secara bersama-sama terhadap kreativitas belajar siswa (Y). Oleh karena itu, di bawah ini secara lebih rinci masing-masing hipotesis akan diuji sebagai berikut:

\footnotetext{
${ }^{14}$ Sugiyono, Metode Penelitian Pendidikan Pendekatan Kuantitatif, Kualitatif, dan R \& D, h.209
} 
1. Pengaruh manajemen pembelajaran guru ( $\left.\mathbf{X}_{\mathbf{1}}\right)$ terhadap gaya belajar (Y)

Tabel 2. Kekuatan Pengaruh (Koefisien Korelasi Sederhana) $\left(\rho_{y 1}\right)$

\section{Correlations}

\begin{tabular}{|c|c|c|c|}
\hline & & $\begin{array}{l}\text { KREATIVITAS } \\
\text { BELAJAR } \\
\text { SISWA }\end{array}$ & $\begin{array}{l}\text { MANAJEMEN } \\
\text { PEMBELAJARAN } \\
\text { GURU }\end{array}$ \\
\hline \multirow{3}{*}{$\begin{array}{l}\text { KREATIVITAS } \\
\text { BELAJAR SISWA }\end{array}$} & $\begin{array}{c}\text { Pearson } \\
\text { Correlation }\end{array}$ & 1 & .292 \\
\hline & Sig. (2-tailed) & & .010 \\
\hline & $\mathrm{N}$ & 78 & 78 \\
\hline \multirow{3}{*}{$\begin{array}{l}\text { MANAJEMEN } \\
\text { PEMBELAJARAN } \\
\text { GURU }\end{array}$} & $\begin{array}{c}\text { Pearson } \\
\text { Correlation }\end{array}$ & .292 & 1 \\
\hline & Sig. (2-tailed) & .010 & \\
\hline & $\mathrm{N}$ & 78 & 78 \\
\hline
\end{tabular}

Keterangan: Interpretasi atau kriteria derajat koefisien korelasi:

$0 \quad$ : Tidak ada korelasi atau tidak ada hubungan

0,10 - 0,25 : Korelasi atau hubungan lemah

0,26 - 0,50 : Korelasi atau hubungan cukup kuat

0,51 - 0,75 : Korelasi atau hubungan kuat

0,76-0,99 : Korelasi atau hubungan sangat kuat

1 : Korelasi atau hubungan sempurna

Berdasarkan tabel 4.12 tentang pengujian hipotesis $\rho_{\mathrm{y} 1} \mathrm{di}$ atas, menunjukkan bahwa pada tingkat kepercayaan 99\% $(\alpha=0,01)$ diperoleh koefisien korelasi sederhana Pearson correlation $\left(\rho_{\mathrm{y} 1}\right)$ adalah 0,292 , dan nilai signifikansi adalah 0,010<0,05. Dengan demikian, maka Ho ditolak dan $\mathrm{Hi}$ diterima, yang berarti bahwa terdapat pengaruh positif, korelasi cukup kuat dan signifikan manajemen pembelajaran guru terhadap gaya belajar. 
Tabel 3. Besarnya Pengaruh (Koefisien Determinasi) $\left(\rho_{y 1}\right)$ Model Summary ${ }^{b}$

\begin{tabular}{|c|c|c|c|c|}
\hline \multicolumn{2}{|c|}{ Mo } & $\mathrm{R}$ & Adjusted & Std. Error of \\
\hline del & $\mathrm{R}$ & Square & R Square & the Estimate \\
\hline 1 & $.292^{a}$ & .085 & .073 & 12.388 \\
\hline
\end{tabular}

a. Predictors: (Constant), MANAJEMEN PEMBELAJARAN

GURU

b. Dependent Variable: KREATIVITAS BELAJAR SISWA

Adapun besarnya pengaruh ditunjukkan oleh koefisien determinasi $R^{2}(R$ square $)=0,085$, yang berarti bahwa manajemen pembelajaran guru memberikan pengaruh terhadap kreativitas belajar siswa sebesar $8,5 \%$ dan sisanya yaitu 91,5\% ditentukan oleh faktor lainnya.

Adapun arah pengaruh atau koefisien regresi sederhana kreativitas belajar siswa atas manajemen pembelajaran guru, adalah sebagai berikut:

Tabel 4. Arah Pengaruh (Koefisien Regresi Sederhana) $\left(\rho_{y 1}\right)$

\section{Coefficients $^{a}$}

\begin{tabular}{|c|c|c|c|c|c|c|}
\hline \multirow{2}{*}{\multicolumn{2}{|c|}{ Model }} & \multicolumn{2}{|c|}{$\begin{array}{c}\text { Unstandardized } \\
\text { Coefficients }\end{array}$} & \multirow{2}{*}{\begin{tabular}{|}
$\begin{array}{c}\text { Standardized } \\
\text { Coefficients }\end{array}$ \\
Beta
\end{tabular}} & \multirow[b]{2}{*}{$t$} & \multirow[b]{2}{*}{ Sig. } \\
\hline & & B & $\begin{array}{l}\text { Std. } \\
\text { Error }\end{array}$ & & & \\
\hline 1 & (Constant) & $\begin{array}{r}67.75 \\
2\end{array}$ & $\begin{array}{r}16.50 \\
3\end{array}$ & & $\begin{array}{r}4 . \\
105\end{array}$ & $\begin{array}{r}.0 \\
00\end{array}$ \\
\hline & $\begin{array}{l}\text { MANAJEM } \\
\text { EN } \\
\text { PEMBELAJ } \\
\text { ARAN } \\
\text { GURU }\end{array}$ & .380 & .143 & .292 & $\begin{array}{r}2 . \\
659\end{array}$ & $\begin{array}{r}.0 \\
10\end{array}$ \\
\hline
\end{tabular}

a. Dependent Variable: KREATIVITAS BELAJAR SISWA

Memperhatikan hasil analisis regresi sederhana, menunjukkan persamaan regresi sederhana (unstandardized coefficients $B$ ) $\hat{Y}=67,752+$ 
0,380 $\mathrm{X}_{1}$ yang berarti bahwa setiap peningkatan satu unit skor manajemen pemebelajaran guru akan mempengaruhi peningkatan skor kreativitas belajar siswa sebesar 0,380 adapun diagram pencar untuk variabel manajemen pembelajaran guru adalah sebagai berikut:

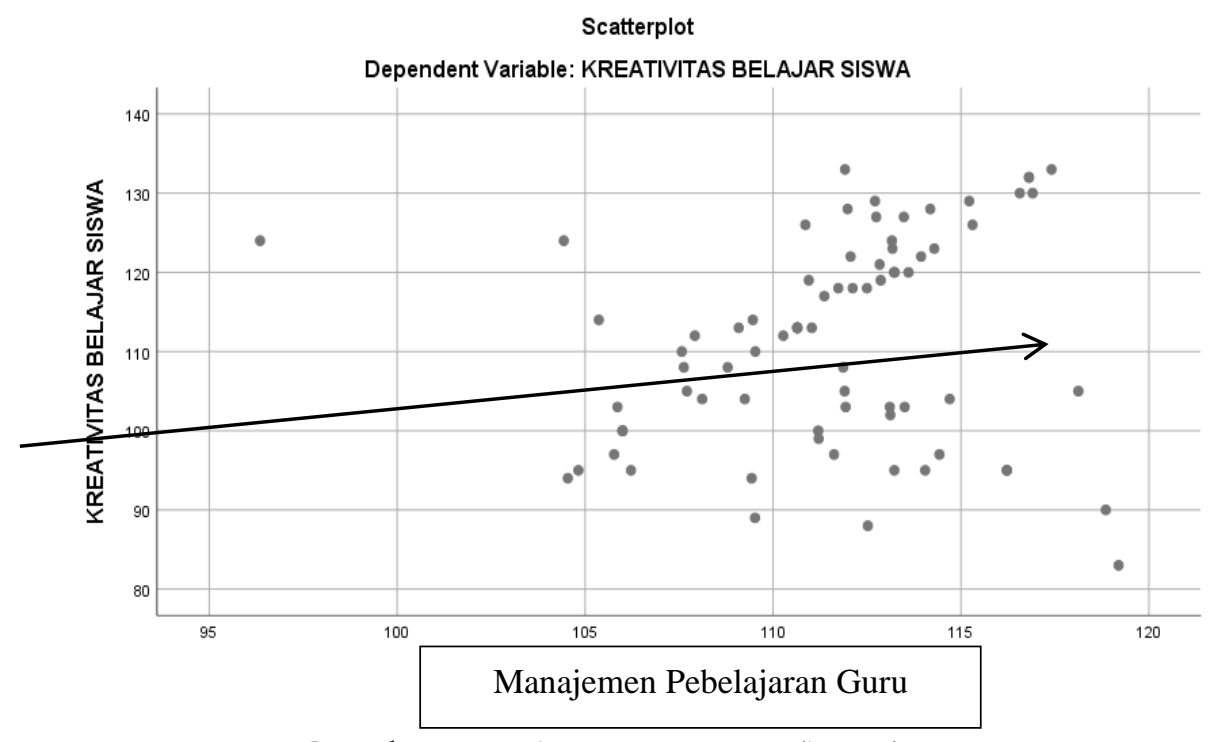

Gambar 1. Diagram Pancar $\left(Y-X_{1}\right)$

2. Pengaruh gaya belajar $\left(\mathbf{X}_{2}\right)$ terhadap kreativitas belajar siswa $(\mathbf{Y})$

Tabel 5. Kekuatan Pengaruh (Koefisien Korelasi Sederhana) $\left(\rho_{y^{2}}\right)$

\section{Correlations}

\begin{tabular}{|c|c|c|c|}
\hline & & $\begin{array}{l}\text { GAYA } \\
\text { BELAJAR }\end{array}$ & $\begin{array}{c}\text { KREATIVITAS } \\
\text { BELAJAR } \\
\text { SISWA }\end{array}$ \\
\hline \multirow[t]{3}{*}{ GAYA BELAJAR } & $\begin{array}{l}\text { Pearson } \\
\text { Correlation }\end{array}$ & 1 & $.301^{* *}$ \\
\hline & Sig. (2-tailed) & & .008 \\
\hline & $\mathrm{N}$ & 78 & 78 \\
\hline \multirow[t]{3}{*}{$\begin{array}{l}\text { KREATIVITAS } \\
\text { BELAJAR SISWA }\end{array}$} & $\begin{array}{l}\text { Pearson } \\
\text { Correlation }\end{array}$ & $.301^{* *}$ & 1 \\
\hline & \begin{tabular}{|c|} 
Sig. (2- \\
tailed)
\end{tabular} & .008 & \\
\hline & $\mathrm{N}$ & 78 & 78 \\
\hline
\end{tabular}

**. Correlation is significant at the 0.01 level (2-tailed). 
Berdasarkan tabel 4.15 tentang pengujian hipotesis $\rho_{\mathrm{y} 2}$ di atas, menunjukkan bahwa pada tingkat kepercayaan 99\% $(a=0,01)$ diperoleh koefisien korelasi sederhana Pearson correlation $\left(\rho_{\mathrm{y} 1}\right)$ adalah 0,301 dan nilai signifikansi adalah 0,008<0,05 . Dengan demikian, maka Ho ditolak dan $\mathrm{Hi}$ diterima, yang berarti bahwa terdapat pengaruh positif walaupun lemah serta signifikan gaya belajar terhadap kreativitas belajar siswa.

Tabel 6. Besar Pengaruh (Koefisien Korelasi Sederhana) $\left(\rho_{y_{2}}\right)$

Model Summary $b$

\begin{tabular}{|cc|c|c|c|}
\hline Model & R & R Square & $\begin{array}{c}\text { Adjusted R } \\
\text { Square }\end{array}$ & $\begin{array}{c}\text { Std. Error of } \\
\text { the Estimate }\end{array}$ \\
\hline 1 & $.301^{\text {a }}$ & .090 & .078 & 12.352 \\
\hline
\end{tabular}

a. Predictors: (Constant), Gaya belajar

b. Dependent Variable: Kreativitas Belajar Siswa

Adapun besarnya pengaruh ditunjukkan oleh koefisien determinasi $R^{2}(R$ square $)=0,090$, yang berarti bahwa manajemen pembelajaran guru memberikan pengaruh terhadap kreativitas belajar siswa sebesar 9,00\% dan sisanya yaitu 81,00 \% ditentukan oleh faktor lainnya.

Adapun arah pengaruh atau koefisien regresi sederhana kreativitas atas gaya belajar, adalah sebagai berikut:

Tabel 7. Arah Pengaruh (Koefisien Regresi) $\left(\rho_{y^{2}}\right)$

\section{Coefficients ${ }^{a}$}

\begin{tabular}{|c|c|c|c|c|c|}
\hline & \multicolumn{2}{|c|}{$\begin{array}{l}\text { Unstandardized } \\
\text { Coefficients }\end{array}$} & $\begin{array}{l}\text { Standardized } \\
\text { Coefficients }\end{array}$ & & \\
\hline Model & B & Std. Error & Beta & $\mathrm{t}$ & Sig. \\
\hline (Constant) & 70.004 & 15.160 & & 4.618 & .000 \\
\hline $\begin{array}{l}\text { GAYA } \\
\text { BELAJAR }\end{array}$ & .344 & .125 & .301 & 2.747 & .008 \\
\hline
\end{tabular}

a. Dependent Variable: KREATIVITAS BELAJAR SISWA 
Memperhatikan hasil analisis regresi sederhana, menunjukkan persamaan regresi sedehana (unstandardized coefficients B) $\hat{Y}=70,004+$ $0,344 \mathrm{X}_{2}$ yang berarti bahwa setiap peningkatan satu unit skor gaya belajar akan mempengaruhi peningkatan skor kreativitas belajar siswa sebesar 0,344 . adapun diagram pencar untuk variabel manajemen pembelajaran guru adalah sebagai berikut:

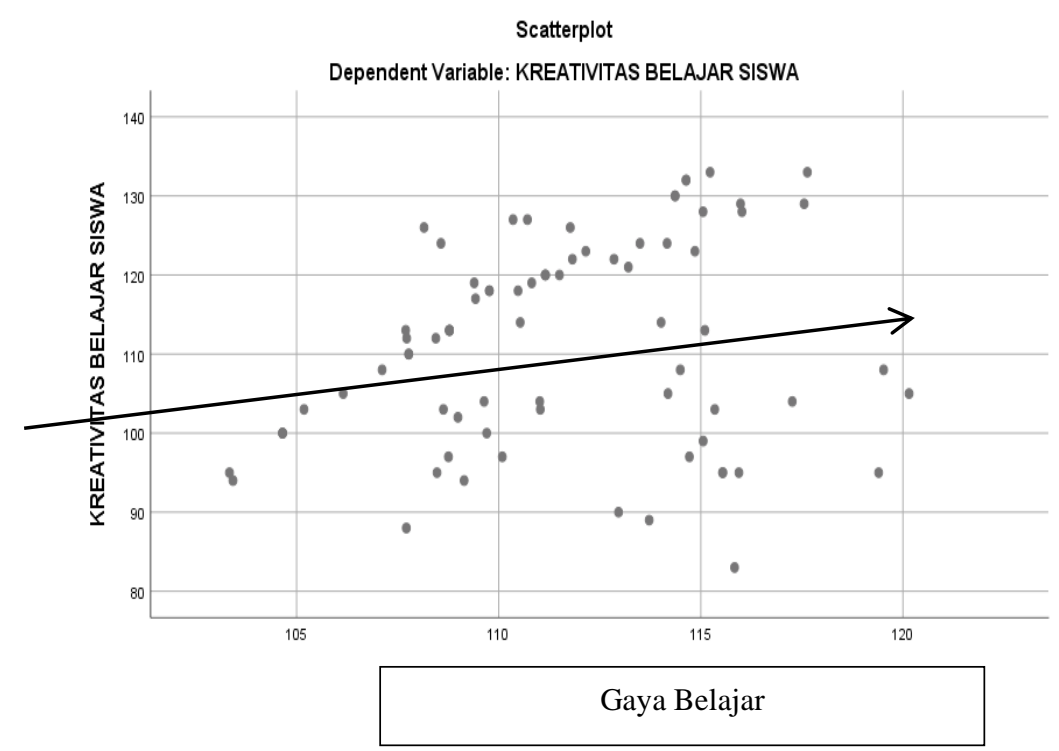

Gambar 2. Diagram Pencar $\left(Y-X_{2}\right)$

3. Pengaruh manajemen pembelajaran guru $\left(\mathbf{X}_{1}\right)$ dan gaya belajar $\left(\mathrm{X}_{2}\right)$ secara bersama-sama terhadap kreativitas belajar siswa $(\mathrm{Y})$ Tabel 8. Kekuatan Pengaruh (Koefisien Korelasi Ganda) $\left(R_{\text {y.1.2) }}\right.$

\begin{tabular}{|c|c|c|c|c|}
\hline \multicolumn{5}{|c|}{ Model Summary } \\
\hline Model & $\mathrm{R}$ & R Square & $\begin{array}{l}\text { Adjusted } \\
\mathrm{R} \text { Square }\end{array}$ & $\begin{array}{r}\text { Std. Error } \\
\text { of the Estimate }\end{array}$ \\
\hline 1 & $.330^{a}$ & .109 & .085 & 12.307 \\
\hline
\end{tabular}

a. Predictors: (Constant), Gaya Belajar, Manajemen

Pembelajaran Guru

b. Dependent Variable: Kreativitas Belajar Siswa 
Berdasarkan tabel 4.18 tentang pengujian hipotesis $\mathrm{R}_{\mathrm{y} .1 .2}$ di atas, menunjukkan bahwa pada tingkat kepercayaan 99\% $(\alpha=0,01)$ diperoleh koefisien korelasi ganda Pearson correlation ( $\mathrm{R}_{\mathrm{y} .1 .2)}$ adalah 0,330 dan nilai signifikansi adalah 0,013<0,05, . Dengan demikian, maka Ho ditolak dan Hi diterima, yang berarti bahwa terdapat pengaruh positif dan cukup kuat serta signifikan manajemen pembelajaran guru dan gaya belajar secara bersama-sama terhadap kreativitas belajar siswa.

Tabel 9. Besarnya Pengaruh (Koefisien Determinasi) $\left(R_{y 1.2}\right)$

Model Summary ${ }^{b}$

\begin{tabular}{|rc|r|r|r|}
\hline $\begin{array}{c}\mathrm{M} \\
\text { odel }\end{array}$ & $\mathrm{R}$ & $\begin{array}{r}\mathrm{R} \\
\text { Square }\end{array}$ & $\begin{array}{r}\text { Adjuste } \\
\text { d R Square }\end{array}$ & $\begin{array}{c}\text { Std. } \\
\text { Error of the } \\
\text { Estimate }\end{array}$ \\
\hline 1 & $.330^{\mathrm{a}}$ & .109 & .085 & 12.307 \\
\hline
\end{tabular}

a. Predictors: (Constant), Gaya Belajar, Manajemen Pembelajaran Guru

b. Dependent Variable: Kreativitas Belajar Siswa

Tabel 10. Koefisien Signifikansi ANOVA ${ }^{a}$

\begin{tabular}{|c|c|c|c|c|c|}
\hline Model & $\begin{array}{r}\text { Sum } \\
\text { of Squares }\end{array}$ & $\begin{array}{l}\mathrm{d} \\
\mathrm{f}\end{array}$ & $\begin{array}{r}\text { Mean } \\
\text { Square }\end{array}$ & $\mathrm{F}$ & Sig. \\
\hline 1 Regression & $\begin{array}{r}1387 . \\
712\end{array}$ & 2 & 693.856 & 4.581 & $.013^{b}$ \\
\hline Residual & $\begin{array}{r}1135 \\
9.737\end{array}$ & $\begin{array}{l}7 \\
5\end{array}$ & 151.463 & & \\
\hline Total & $\begin{array}{r}1274 \\
7.449\end{array}$ & $\begin{array}{l}7 \\
7\end{array}$ & & & \\
\hline
\end{tabular}

a. Dependent Variable: KREATIVITAS BELAJAR SISWA

b. Predictors: (Constant), GAYA BELAJAR, MANAJEMEN PEMBELAJARAN GURU

Adapun besarnya pengaruh ditunjukkan oleh koefisien determinasi $R^{2}(R$ square $)=0,109$, yang berarti bahwa manajemen pembelajaran guru dan gaya belajar secara bersama-sama memberikan pengaruh terhadap kreativitas belajar siswa sebesar 10,9\% dan sisanya yaitu 89,1 \% ditentukan oleh faktor lainnya. 
Adapun arah pengaruh atau koefisien regresi ganda kreativitas belajar atas manajemen pembelajaran guru dan gaya belajar secara bersama-sama adalah sebagai berikut:

Tabel 11. Arah Pengaruh (Koefisien Regrensi Ganda) $\left(R_{y} .1 .2\right)$

\section{Coefficients $^{\mathrm{a}}$}

\begin{tabular}{|c|c|c|c|c|c|}
\hline \multirow[b]{2}{*}{ Model } & \multicolumn{2}{|c|}{$\begin{array}{r}\text { Unstandard } \\
\text { ized Coefficients }\end{array}$} & \multirow{2}{*}{\begin{tabular}{|c} 
Stan \\
dardized \\
Coefficie \\
nts \\
\\
Beta \\
\end{tabular}} & \multirow[b]{2}{*}{$t$} & \multirow[b]{2}{*}{ Sig. } \\
\hline & B & $\begin{array}{r}\text { St } \\
\text { d. Error }\end{array}$ & & & \\
\hline$($ (Constant) & 58.752 & 17.588 & & 3.340 & .001 \\
\hline $\begin{array}{l}\text { MANAJEMEN } \\
\text { PEMBELAJARAN } \\
\text { GURU }\end{array}$ & .224 & .180 & .172 & 1.249 & .216 \\
\hline GAYA BELAJAR & .223 & .158 & .195 & 1.414 & .162 \\
\hline
\end{tabular}

a. Dependent Variable: Kreativitas Belajar Siswa

Memperhatikan hasil regresi ganda menunjukan persamaan regresi (unstandardized coefficients B) $\hat{Y}=58,752+0,224 X_{1}+0,223 X_{2}$ yang berarti bahwa setiap peningkatatn satu unit skor manajemen pembelajaran guru dan gaya belajar secara bersama-sama akan mempengaruhi peningkatan skor kreativitas belajar siswa sebesar 0,447.

\section{Kesimpulan dan Saran}

Berdasarkan hasil pengujian hipotesis yang telah diuaraikan di atas, maka secara keseluruhan temuan dalam penelitian ini, dapat menjawab rumusan masalah yang telah dipaparkan, adapun hasil dari analisa data menggunakan metode statistik. Terdapat hubungan positif, cukup kuat dan signifikan antara manajemen pembelajaran guru dengan kreativitas belajar siswa, yang ditunjukkan oleh koefisien korelasi sederhana (ry.1) adalah 0,292 (korelasi kuat) dan koefisien determinasi $\left(\mathrm{R}^{2}\right)=0,085$, yang berarti bahwa manajemen pembelajaran guru memberikan pengaruh terhadap kreativitas belajar siswa sebesar 8,5\% dan sisanya yaitu 91,5\% 
ditentukan oleh faktor lain. Sedangkan persamaan regresi sederhana $\hat{Y}=$ $67,752+0,380 \mathrm{X}_{1}$, yang berarti bahwa setiap peningkatan satu unit skor manajemen pembelajaran guru akan memberikan kecendrungan terhadap peningkatan kreativitas belajar siswa sebesar 0,380. Hubungan tersebut diperkuat dengan hasil penelitian kualitatif, yang mengungkapkan bahwa manajemen pembelajaran guru dapat memberikan peningkatan terhadap kreativitas belajar siswa. Dengan demikian, maka setiap perencanaan manajemen pembelajaran guru akan diikuti dengan peningkatan kreativitas belajar siswa, dengan kata lain manajeman pembelajaran guru dapat mempengaruhi kreativitas belajar siswa. Terdapat hubungan positif, cukup kuat dan signifikan antara gaya belajar dengan kreativitas belajar siswa, yang ditunjukkan oleh koefisien korelasi sederhana (ry.2) adalah 0,301 (korelasi cukup kuat) dan koefisien determinasi $\left(R^{2}\right)=0,090$, yang berarti bahwa gaya belajar memberikan kontribusi terhadap kreativitas belajar siswa sebesar 9,00\% dan sisanya yaitu $81,00 \%$ ditentukan oleh faktor lain. Sedangkan persamaan regresi sederhana $\hat{Y}=70,004+0,344 \mathrm{X}_{2}$, yang berarti bahwa setiap peningkatan satu unit skor gaya belajar akan memberikan kecendrungan terhadap peningkatan skor kreativitas belajar siswa 0,344. Hubungan tersebut diperkuat dengan hasil penelitian kualitatif, yang mengungkapkan bahwa gaya belajar dapat memberikan sumbangan terhadap peningkatan kreativitas belajar siswa. Dengan demikian, maka setiap peningkatan gaya belajar akan diikuti dengan peningkatan kreativitas belajar siswa, dengan kata lain gaya belajar dapat memprediksi tinggi rendahnya kreativitas belajar siswa.

Terdapat hubungan positif, kuat dan signifikan antara manajmen pembelajarn guru dan gaya belajar secara bersama-sama dengan kreativitas belajar siswa, yang ditunjukkan oleh koefisien korelasi ganda (Ry.1.2) adalah 0,330 (korelasi kuat) dan koefisien determinasi $\left(R^{2}\right)=0,109$, yang berarti bahwa manajmen pembelajarn guru dan gaya belajar secara 
bersama-sama memberikan pengaruh terhadap kreativitas belajar siswa 10,9\% dan sisanya yaitu 89,1\% ditentukan oleh faktor lain. Sedangkan persamaan regresi ganda $\hat{Y}=58,752+0,224 \mathrm{X}_{1}+0,223 \mathrm{X}_{2}$, yang berarti bahwa manajmen pembelajarn guru dan gaya belajar secara bersama-sama dengan kreativitas belajar siswa memberikan pengaruh 0,447. Hubungan tersebut diperkuat dengan hasil penelitian kualitatif, yang mengungkapkan bahwa manajemen pembelajaran guru dan gaya belajar secara bersama-sama dapat memberikan sumbangan terhadap peningkatan kreativitas belajar siswa. Dengan demikian, maka setiap peningkatan manajemen pembelajaran guru dan gaya belajar secara bersama-sama akan diikuti dengan peningkatan kreativitas belajar siswa, dengan kata lain manajemen pembelajaran guru dan gaya belajar secara bersama-sama dapat memprediksi tinggi rendahnya kreativitas belajar siswa.

\section{Saran}

Berdasarkan pembahasan hasil penelitian, kesimpulan dan implikasi sebagaimana telah dikemukakan di atas, maka disampaikan saran-saran sebagai berikut:

1. Dalam proses pembelajaran guru seharusnya menciptakan suasana belajar yang menyenagkan, menciptakan ide-ide yang menarik dalam proses pembelajaran, dan memberikan penghargaan (reward) terhadap siswa yang berprestasi dikelas bisa dilakukan agar siswa makin giat untuk belajar.

2. Guru harus bisa memperhatikan dan membimbing kepada siswa yang belum berprestasi dikelas dengan memberikan motivasi dan masukan agar siswa merasa diperhatikan oleh guru

3. Sekolah harus memfasilitasi guru untuk dapat mengikuti pelatihan-pelatihan dalam hal penggunaan metode belajar, melakukan pendekatan terhadap guru agar bisa bersma-sama mewujudkan tujuan pembelajaran. 
4. Perlu adanya peran orang tua dalam meningkatkan kreativitas belajar siswa, dengan cara guru melakukan komunikasi terhadap orang tua siswa untuk memberi tahu keadaan siswa disekolah dan apa yang kurang dengan siswa tersebut, sehingga orang tua mempunyai peran untuk mengingatkan siswa untuk belajar dirumah.

5. Bagi peneliti lainnya hendaknya melakukan penelitian sejenis dengan obyek dan subyek yang berbeda untuk lebih memperkarya khasanah ilmu pegetahuan.

\section{Daftar Pustaka}

Adi W., Gunawan., 2002, Genius Learning Strategy, Petunjuk Praktis untuk Bermain untuk Membuka Pikiran Anak-anak Anda, terj. Rahmi Astuti, Bandung: Kaifa.

Andrianto, Juhan Taufiq., 2018, Cara Cerdas Melejitkan IQ Kreatif Anak, Bandung: Remaja Rosdakarya.

As-Suyuthi, Imam, Tafsir Jalalain, Jilid, 4, 2498.

E.B Hurlock, 1980, Perkembangan Anak Jilid II. Alih Bahasa Meltasari Tjandrasa. Jakarta: Penerbit Erlangga.

Ghufron,M. Nur dan Risnawati, Rini S, 2013, Gaya Belajar Kajian Teoretik, Yogyakarta: Pusaka Pelajar.

Nasution, 2009, Berbagai Pendekatan dalam Proses Belajar Mengajar, Jakarta: PT. Bumi Askara.

Porter, Bobbi De dan Hernacki, Mike., 2010, Quantum Learning, Membiasakan Belajar Nyaman dan Meyenangka, Bandung: Kaifa.

Republika Online, 2019, Kurikulum 2013, Tekanan Karakter Ciptakan Siswa Lebih Kreatif dan Inovatif ,https://www.republika.co.id/berita/kemendikbud/testimoni-k13/14/09/12/nbsgn5-

kurikulum-2013- tekankan-karakter-ciptakan-siswa-lebih-aktif-dan-kreatif (di akses pada 05/09/2019 jam, 21:03)

Russeffendi, E.T., 1998, Dasar-dasar Penelitian Pendidilkan dan Bidang Non Eksakta lainnya, Bandung, Tarsito. 
Sanjaya, Wina., 2006, Strategi Pembelajaran, Jakarta: Prenadamedia Group.

Siswanto, 2009, Pengantar Manajemen, Jakarta: Bumi Aksara, cet. Kelima.

Sugiyono, 2015, Metode Penelitian Pendidikan Pendekatan Kuantitatif, Kualitatif, dan R \& D.

Supriadi ,Dedi., 1994, Kreativitas, Kebudayaan dan Perkembangan Iptek. Bandung:Alfabeta.

Tim, 2005, Kamus Besar Bahasa Indonesia, Jakarta: Balai Pustaka. 